\title{
Using Role Play Activities to Teach The Present Perfect Tense
}

\begin{abstract}
:
Teaching languages has continuously been centered on teaching their grammars which in turn focuses on teaching tenses. This research aims at investigating the effectiveness of using Role Play to teach the Present Perfect. It also seeks to analyze the attitudes of grammar teachers and their implementation of Role Play to teach the Present Perfect, at the Department of Letters and English, University 'Des Frères Mentouri', Constantine. We hypothesize that, first, if teachers of grammar are made aware of the importance of using Role Play to teach the Present Perfect, they will have positive attitudes towards its implementation in their own classes. Second, if teachers use Role Play in their teaching of the Present Perfect, it will help the students understand and use this tense adequately. To test our hypotheses, a Teachers' Questionnaire and a Students' Test are used. The analysis of the questionnaire shows that teachers of grammar hold positive attitudes towards using Role Play to teach the Present Perfect which totally confirms our first hypothesis. The sample (70 learners) is taken from second year students of English, at the Department of Letters and English, University 'Des Frères Mentouri', Constantine, during the academic year 2014/2015. The results obtained from the test partially confirm the second hypothesis, in other words, Role Play has succeeded to some extent to better the students' understanding and use of the Present Perfect.
\end{abstract}

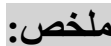

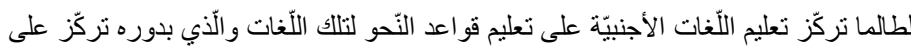

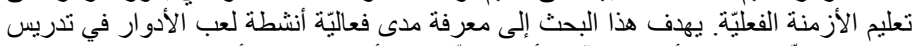

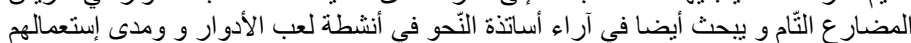

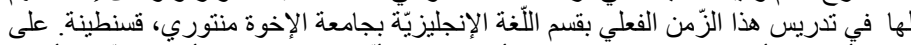

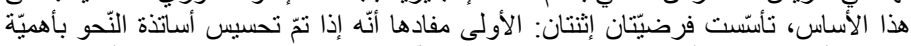

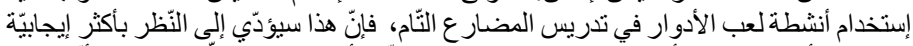

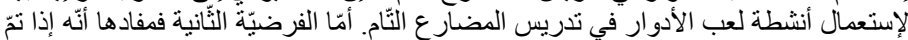

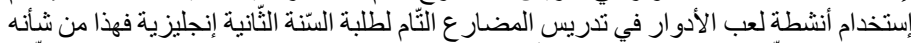

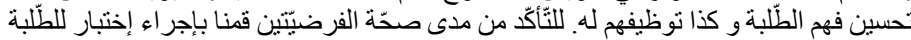

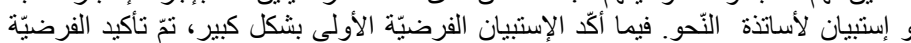

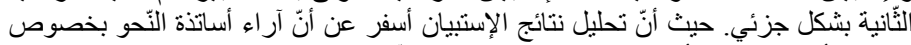

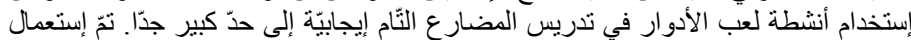

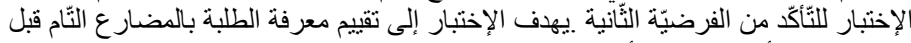

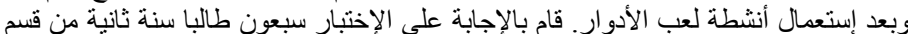

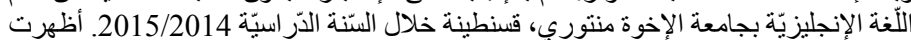

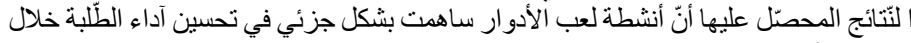

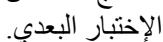

\section{CHOUIEB Samia}

Département de la langue Anglaise Université des Frères Menrouri Constantine 1

\section{Introduction :}

Grammar has always been the subject of interest to a considerable number of researchers whose main objective is to suggest solutions to the learners' various areas of difficulty in learning it. More precisely, the field of teaching tenses has gained more interest among all the other grammar components that have been researched over the years. The questionnaire results obtained from our study shows that $85.71 \%$ of the teachers of grammar at the Department of Letters and English, University 'Des Frères Mentouri', Constantine agree that the Perfect tenses are the most difficult to learn. They further argue that more attention should be paid to the issue of teaching grammar at the Department. 


\section{Theoretical Background}

The theory on which the present research work is based consists of three main concepts related to teaching Grammar, teaching tenses and the theory of Role Play.

\subsection{Teaching Grammar}

Grammar is referred to, by Thornbury (1999, p. 12) as the "sentencemaking machine". This means that grammar is the linguistic tool that is responsible for the arrangement and structuring of all types of sentences. The outstanding schools of Grammar which dominated the field of Second Language Acquisition over history were: Traditional Grammar, De Saussure's Structural Grammar, Chomsky's Transformational Generative Grammar and Halliday and Hassan's Systemic Functional Grammar. According to Purpura (2004, p. 5), the purpose behind instruction, at the time where Traditional Grammar was dominating, was to enable learners to read literature written in Latin and Greek. In addition to this, this school of Grammar aimed at developing the learner's intellect which will accordingly control her will and action making out of her a virtuous member in society. Structural Linguistics, on the other hand, had as its main objective to provide a linguistic analysis of both forms of language i.e. oral as well as written. De Saussure distinguishes between 'Langue' and 'Parole'. This dichotomy is concerned with the idea that 'Langue' refers to the linguistic competence of the community of language speakers, whereas 'Parole' expresses everyone's individual performance. Purpura (2004, p. 9) believes that "structural grammars, associated with linguists such as Bloomfield (1933) and Fries (1940), offered a fairly rigorous method for describing the structure of a language in terms of both its morphology and its syntax".

Though structuralism did not arrive at providing a complete and comprehensive model of grammar teaching, Second Language Acquisition researchers did not give up. One of these scholars is Noam Chomsky who came with the idea of Transformational Generative Grammar in 1957 through the publication of his eminent book 'Syntactic Structures'. The idea of Universal Grammar generates the shared aspects of languages, and claims that all languages can be traced to the same common origin. Therefore, the deep structure of all languages is the same though they seem to differ as we look at their surface structure. Purpura (2004, p. 10) claims that the "underlying properties of any individual language system can be uncovered by means of a detailed, sentence level 
analysis", through the use of phrase structure diagrams, according to the Universal Grammar principles set by Noam Chomsky. The other school of grammar which dominated grammar teaching some time after the Transformational Generative Grammar is Systemic Functional Grammar. It is an approach to grammar teaching that views language mainly as a means of communication and emphasizes the notion of language and meaning. As the name suggests, this approach to language teaching focuses on two main points; the first one deals with the idea that language is made up of 'systems' rather that being a simple set of rules, and the second idea concerns the 'functions' of language such as 'experiential', 'interpersonal' and 'textual', or in other words, 'Mood', 'Transitivity' and 'Theme'. Those three language functions are defined by Purpura (2004, p. 19) as the set of "...experiential functions used to express experience, interpersonal functions used to establish and maintain social ties, and textual functions used to structure information in oral and written texts".

\subsection{Teaching Tenses}

Declerck $(2015$, p. 1) states that "tense is a subject on which the last word has not yet been said" which indicates that the problem of teaching tenses, though it has been dealt with largely by researchers, is still unsolved. The complexity of most tenses in English is related to the two notions of time frame and aspect. Time is defined by Declereck et al (2006, p. 94) as "an extralinguistic category, i.e. it exists independently of language". We say 'past time' to refer to the entire period before the present that is unlimited in the past, and the same thing is true for the future which refers to all what will happen after now that is the present time or the moment of speech to which almost all actions are referred. According to Quirck et al (1985, p. 175; cited in Declerck 2015, p. 16), we may distinguish two types of time: 'physical' and 'linguistic'. Physical time "exists in abstraction from any given language", whereas linguistic time is "time as it is perceived and talked about by language users". Aspect, on the other hand, gives extra information about how the action happens or how it is performed. There are four aspects in English: simple (at the time), progressive / continuous (in progress during that time), perfect (before that time), perfect progressive (in progress during and before that time). When we combine the three time frames and the four aspects, we get 12 possible combinations of forms, called tenses. The name of each tense tells which time frame and which aspect are being used as shown in the following table: 


\begin{tabular}{|c|c|c|c|l|}
\hline \multirow{2}{*}{$\begin{array}{c}\text { Time } \\
\text { Frame }\end{array}$} & \multicolumn{4}{|c|}{ Aspects } \\
\cline { 2 - 5 } Present & Pr. S & Pr. C & $\begin{array}{c}\text { Pr. } \\
\text { Perf. }\end{array}$ & Pr. Perf. C \\
\hline Past & PS & PC & P Perf. & P Perf. C \\
\hline Future & FS & FC & F Perf. & F Perf. C \\
\hline
\end{tabular}

Table 01: The English Tenses

Another very important distinction has to be made between absolute and relative tenses. An absolute tense is a tense that takes the temporal zero point (the moment of speech) as its reference time; it is directly related to it such as the past simple, the present perfect and future simple. The most important thing in the absolute tenses is that they do not relate to any other tense as their reference time. According to Comrie (1976, p. 36 ), the term absolute tense "has come to be used to refer to tenses which take the present moment as their deictic centre". He argues that the term absolute is a bit confusing or misleading because, according to him, the present moment is just one of a number of similar points that may be considered as reference time points. He thus adopted his definition to this factual aspect, he continues to say that the absolute tense " should be interpreted to mean a tense which includes as part of its meaning the present moment as deictic centre; whereas relative tense refers to a tense which does not include as part of its meaning the present moment as deictic centre". The present simple is an absolute tense, if we apply Comrie's definition we'll find that the present tense indicates an action that part of it includes the present moment. The same thing may be applied to the present perfect simple and continuous which, though started in the past, may extend until the present moment in some cases. Declerck et al (2006, p. 120) points out that "we speak of an ABSOLUTE TENSE when the tense in question relates the situation time directly to [the temporal zero point]".

As to the teaching of the Present Perfect tense, it has profoundly been researched by Second Language Acquisition teachers and researchers. The principal aim behind their research works has been to find the best method to teach it. According to Scrivener (2010, p. 157), the present perfect is used to convey three main functions which are: (1) Talking about someone's past experience. Scrivener (2010) finds it very effective 
to start teaching this first function of the present perfect by asking students the question "have you ever...?" which means "have you at any time in the past done some particular thing?' Another function of the present perfect is (2) expressing recent past events, generally through the use of the adverb of time 'just' or other similar adverbs. Scrivener (2010, p. 160) gave the following examples:

I've just announced that our train will be delayed.

Their latest car has just gone into production.

The present perfect may also be used to express (3) a past action that has not yet finished, or as Scrivener (2010, p. 161) refers to it, an "up to now" event. This meaning of the present perfect is divided into three submeanings which are shown by Scrivener (2010, p. 163-4) as follows: (3a). Past events that "happened once or a number of times in an unfinished period of time that started in the past and continued up to now. In many cases the connection to now is not stated but we can still guess it". For example,

We've been burgled! (and now we don't have a TV).

I've already spent this month's salary (and now I've none left).

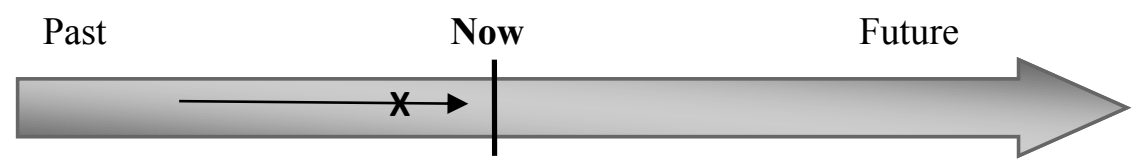

Figure 01: Present Perfect Simple to Express Actions that Happened

Once at Some Time in the Past and Continued Up to Now

I've already had two foreign holidays this year.

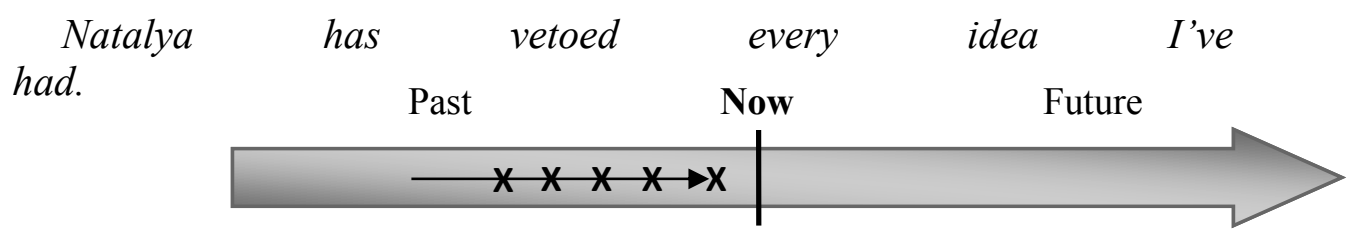


Figure 02: Present Perfect Simple to Express Actions that Happened a Number of Times in the Past and Continued up to Now

(3b). We use the present perfect to show that there is a change in a given past situation, for example:

Sales have shown a slight improvement this year.

I've put on two kilos in the last month.

The business has grown very fast.

(3c). The present perfect is used also to express "states that started in the past and continued up to now (and may go on into the future). Consider the following examples:

My family has lived in this area for years. (and still is)

Greece has been a republic since 1973 (and still is)

Dr Watson has worked in the region for 40 years. (and still is)

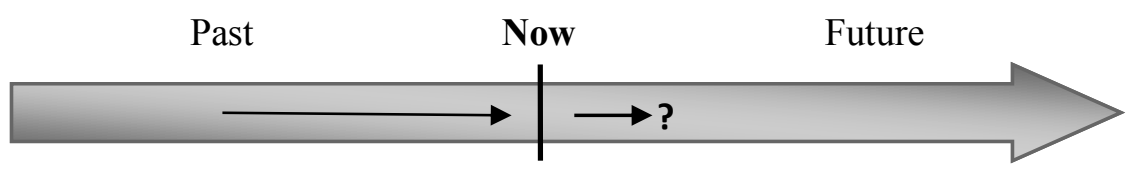

Figure 03: Present Perfect Simple to Express Actions that

Happened in the Past and Continued up to Now and May continue into the Future

The Present Perfect Progressive is not as much used as the Present Perfect Simple in English for the simple reason that the latter may convey the same function as the former with exactly the same meaning which minimizes the use of the Present Perfect Progressive. It refers to an action that has been taking place at some time before 'now', and is seen as not yet completed. Scrivener (2010, p. 174) explains that the two forms "refer 
to exactly the same time", however, the present perfect progressive consider the 'ongoing' perspective of the action. Look at these examples:

I've worked in the garden all day.

I've been working in the garden all day.

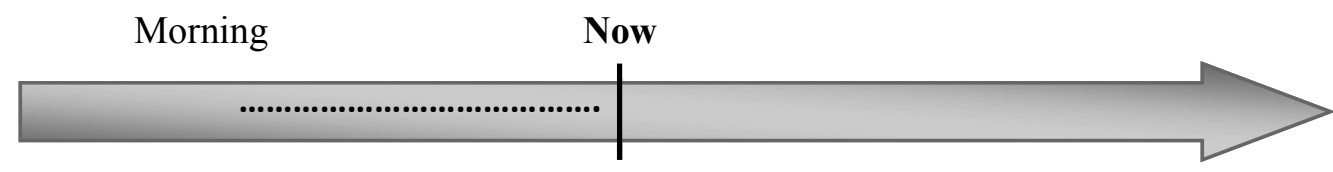

Figure 04: The Present Perfect Progressive to express Actions Up to Now

When the speaker uses the present perfect progressive instead of the present perfect simple, he's rather emphasizing the 'duration of the action' rather than the action itself in situations of 'complaining' about undesired realities and 'criticizing'. Scrivener (2010, p. 175) suggests the following examples:

I've been filling in this form all evening.

I've been waiting for over an hour.

I've been chasing round all day buying presents.

I've been calling him for weeks but I still haven't made contact.

In all these sentences, the action seems to have been taking place for a given period of time and may continue taking place at some time after 'now'. The present perfect progressive is not used so much in English because the single meaning it conveys may be conveyed through the use of the present perfect simple. As we have mentioned so far in this section, we use it exclusively to complain or criticize.

\subsection{Role Play as a Teaching Strategy}

Role play activities, a category of language games, provide the learners with more opportunities to act and react to the different situations that they may encounter in a foreign language context. They are seen as developing the learners' performance in order for this to concord with the linguistic competence they already have. Killen (2007, p. 280) believes that role play can be defined as being "an unrehearsed dramatization in which individuals improvise behaviours that illustrate acts expected of persons involved in defined situations". This definition tackles important aspects 
as to classroom role play activities which consists of acting out real-life situations, i.e. students are introduced to the different communication settings that are authentic, or as Ladousse $(1987$, p. 5) puts it "they have direct experience of the unpredictable nature of language in use". Linguistic knowledge is of no value if it is not used for communicative purposes. Ladousse (1987, p. 6) recounts the very funny, but expressive, anecdote of the student in the supermarket in Britain who was astonished when he knew that all what he learned so far in his textbook was useless when it comes to "unpredictable" language. In order for a Role play to be successful and more effective, it should be well-prepared. Ladousse (1987, p. 12) suggests the following tips as for the well organization of a role play in the language class.

1. Do not care a lot about noise unless in disturbs the teachers next door.

2. Introduce pair work before group work. Face-to-face communication decreases the learners' anxiety and let them feel ready to start working in larger groups.

3. Do not opt for very long role plays right from the beginning.

4. Prepare a role play that fits with different numbers of learners because you might have some absentees among learners.

5. Give clear instructions before learners start playing their roles and make sure their roles are clear for them.

6. Do not care about the minority of learners who are not seriously taking part in the task. We usually find such a group of learners in any class. If they are not really disturbing the flow of the activity, do not get bothered.

7. Avoid difficult role plays with a lot of emotions and feelings at the beginning of your RP activities. This is to avoid learners breaking into their MT. in case learners shifted to their MT just for a word which they do not know, do not make out of this a big problem.

8. In case learners are using their LI a lot, here, you should slow down and go in your activity step by step. Start with pair work and try to introduce a simple role play where learners are simply required to fill in the gaps. If this did not work, then you have a serious problem of motivation to learn which you have to solve whatsoever.

9. Opt for follow up activities for students who will finish their role play first.

10. Pay attention to time; you have to limit your students to $\mathrm{X}$ time that they must not exceed. 
Killen (2007, p. 282) summarizes the main reasons behind using role play in one's class in three main ones. First, encouraging learners to maintain social interaction (Piaget, 1972) by acting out different social roles, second, challenging learners (Vincent \& Shepherd 1998, p. 2) through getting them try something that is not fixed and full of surprises which encourage learners to learn to take risks, and finally bringing "realism" to the class through creating a kind of meaningful input from which learners could start their learning experience. According to Killen (2007, p. 290-291), role play can be used to teach a variety of disciplines including "Foreign Language Teaching, Teaching English, Teaching science",...etc. According to him, teachers of those disciplines prefer to use role play for the main three reasons that we have just mentioned. The writer further explains that RP does not only serve the achievement of "the acquisition of knowledge", but also "the application of knowledge to develop further understanding and skills, and attitudinal change". Furthermore, Killen (2007, p. 282-283) states fifteen achievements that one may realize when using RP in their class. The ones that interest our study are paraphrased in the following notes:

1. Motivation to learn.

2. Applying knowledge to real life contexts.

3. Developing communicative social skills.

4. Learners benefit from risk taking to learn how to deal with different types of issues.

5. Turning learners from passive to active participants in the classroom.

6. "Experiencing situations rather than just hearing or reading about them".

7. Developing learners" "self-confidence, self-esteem, self-image".

8. "Help ESL learners to understand important concepts that are difficult for them to understand through verbal explanations".

\section{The Study}

\subsection{The Teachers' Attitudes and Methodology of Teaching the Present Perfect}

The questionnaire is meant to gain information as to the teachers' attitudes towards using Role Play activities to teach the Present Perfect tense. It also seeks to analyze their methods of teaching tenses. The results obtained from the questionnaire have shown that the teachers' attitudes towards the use of RP to teach the present perfect are very positive. Table 02 illustrates the point: 
CHOUIEB Samia

\begin{tabular}{|l|c|c|}
\hline Options & $\mathbf{N}$ & $\mathbf{\%}$ \\
\hline Yes & 12 & 85.71 \\
\hline No answer & 02 & 14.29 \\
\hline Total & $\mathbf{1 4}$ & $\mathbf{1 0 0}$ \\
\hline
\end{tabular}

Table 02: Teachers' Opinions about the Use of Role Play in Teaching

However, a small minority of teachers do use Role Play in their teaching, according to table three below.

\begin{tabular}{|l|c|c|}
\hline Options & N & \% \\
\hline Yes & 02 & 14.29 \\
\hline No & 12 & 85.71 \\
\hline Total & $\mathbf{1 4}$ & $\mathbf{1 0 0}$ \\
\hline
\end{tabular}

Table 03: Teachers' Use of Role Play to Teach the

\section{Present Perfect}

When we asked the teachers about the methods they use to teach tenses, the majority told us that they adopt an eclectic method in teaching tenses. $21.43 \%$ did not understand the question as they ticked the three options: deductively, inductively and eclectically.

\section{Table 04: \\ Teaching}

2.2.The

of

\begin{tabular}{|c|c|c|}
\hline Options & $\mathbf{N}$ & $\mathbf{\%}$ \\
\hline $\mathbf{a}$ & 02 & 14.29 \\
\hline $\mathbf{b}$ & 01 & 07.14 \\
\hline $\mathbf{c}$ & 08 & 57.14 \\
\hline abc & 03 & 21.43 \\
\hline Total & $\mathbf{1 4}$ & $\mathbf{1 0 0}$ \\
\hline
\end{tabular}

\section{Methods of}

Tenses

Students' Use

Present Perfect

The aim behind the experiment is to verify whether and to what extent Role Play enhances the learning of the Present Perfect tense. The sample investigated in our research is taken randomly from the larger population of second year students of English, at the Department of Letters and English, University 'Des Frères Mentouri' Constantine. It is made up of 70 students: 35 students constitute the Experimental Group and the other 35 make up the Control Group.

The test is made up of three parts. The first part is in the form of a "Fill in the blanks" with the correct form of the tense out of the two suggested 
tenses in the dialogues. In the first dialogue, there is a set of eight (08) gaps, and in the second one we have included seven (07) gaps. The students, in this activity, are required to choose between two verbs, one is in the past simple tense and the other one is in the present perfect simple tense. The aim behind choosing the past simple is to confirm our prejudgment which says that the learners, most of the time, misuse the present perfect tense because they use other tenses instead (most probably the past simple). They tend to generalize the notion of time of the past simple tense to express both the functions of the present perfect tense and the past simple tense. This may have diminished the importance of the present perfect tense for them as they think that the two tenses are identical; however, they possess two different conceptualizations as to their expression of time relations. Part two is called a 'filling in the gaps' activity consisting of thirteen items. These are sentences where the students are required to decide which tense suits which blank. The blanks can be filled with either the present perfect, simple or continuous, or the past simple tense. However, most of the blanks require the use of the present perfect tense. The third part of the test is a 'multiple choice' activity. This time, the activity is designed to check one single specific point that is the students' comprehension of the present perfect time markers. This activity is made up of six sentences; each sentence requires the use of a given adverb of time that is different from the other sentences. The learners are given four multiple choices to ensure that their choice of one rather that the other adverb is done after a deep reflection. The adverbs given are 'never', 'since', 'yet', 'already', 'ever' and 'for'. The same test is administered to both the $C G$ and the Exp. $G$ at the beginning of the academic year 2014-2015 for the pre-test as well as the post-test. We did not make any changes in the test before and after instruction to ensure that the learners' level of achievement is not influenced by any factors interior to the type of test used. The test is attached in the appendices' section at the end of our research work. The research instrument is the percentage.

The instruction took place during two sessions because the first lesson tenses for second year students includes all the English tenses, thus, one tense that is the Present Perfect, cannot take more than two sessions. It was planned to go through two stages; each of which has its main objective. The first part of the instruction took place first when the learners were given two different dialogues. After this, each pair of learners was asked to read the dialogues carefully, for several times to check that they have understood the meaning. Next, the pairs were asked to come to the 
board one by one to perform each of the two roles in the dialogues. The first pairs hesitated a bit, however; it has quickly become something they enjoyed and performed in the best way. These dialogues were performed by learners in the first session of instruction and were followed by some questions and discussion about the Present Perfect tense. The students were asked to highlight the verbs that are in the Pre. Per. tense and identify whether it is the Present Perfect simple or Progressive. They were asked questions as to why the Present Perfect is used in the highlighted instances and whether they can replace it with any other tense. Learners seemed to be confused because they could not locate the Present Perfect actions appropriately within the timeline because they were confused between the past and the present time-spheres and whether the Present Perfect belongs to the former or to the latter. In the second session, a free Role Play was used. It is entitled 'Searching for the best babysitter'. The learners were divided into two groups: a group of 'couples', a male and a female learner, and a group of 'babysitters'. The couples are expected to be searching for a babysitter for their new-born baby. They care a lot about the person with whom the baby will spend most of its time when the parents are at work, or doing any other tasks. Therefore, they started asking the babysitter questions like:

Q1: Have you ever taken care of any babies before?

Q2: Have you ever taken drugs?

Q3: Have you ever been to prison?

Q4: Have you ever married and do you have any children?

Q5: How long have you been doing this job?

The babysitters asked questions like:

Q1: Has your baby been to the hospital before?

Q2: Have you ever tried to talk to your baby?

Q3: Has your baby suffered from any health problems before?

Q4: What is its favorite toy?

The examples of questions I included above were asked by students while performing the Role Plays. They were not well formulated, but I tried during Role Play performance to stop from time to time to highlight a correct use of the Present Perfect, or to correct a wrong one. The learners were very motivated and started integrating within their roles and forgot that they were learning grammar. They went further than expected, they started talking about the salary and negotiating together in a very safe and comfortable way. At the same time as they were acting their roles out, the 
researcher teacher was taking some notes and instances of language as used by learners for further classroom discussion.

\section{- Results of the Pre-test}

Part One: Activity One: Fill in the blanks with the correct form of the tense out of two suggested tenses in the following dialogues.

We will consider, in this comparison of the results obtained by the CG and the Exp. G in the pre-test, the average percentage of correct answers for the use of the past simple and that of the present perfect. As far as the $\mathrm{CG}$ is concerned, the average percentage of correct answers for the past simple is $86.43 \%$ and that of the present perfect is $48.05 \%$. However, for the Exp. G, the average percentage of correct answers for the past simple is $90.71 \%$, and that of the present perfect is $43.89 \%$. In other words, the starting level of the CG, concerning the use of the Present Perfect, is slightly better than that of the Exp. G. Concerning the use of the past simple, the average percentage of correct use for the Exp. $G$ is slightly higher than that of the CG. In short, the students in the CG seem to outperform those in the Exp. $G$ in the first part of the pre-test. The following table illustrates the point:

\begin{tabular}{|c|c|c|}
\hline & $\begin{array}{l}\text { Use of the Present Perfect } \\
(\%)\end{array}$ & $\begin{array}{l}\text { Use of the Past Simple } \\
(\%)\end{array}$ \\
\hline CG & 48.05 & 86.43 \\
\hline Exp. G & 43.89 & 90.71 \\
\hline
\end{tabular}

Table 05: Comparison of the results, Pre-test, Part 1

Part Two: Fill in the blanks with the right tense

Activity two requires the learners to fill in the blanks with the right tense; they are given the infinitive between brackets. The table below summarizes the CG and the Exp. G average percentage of correct answers for the second part of the test.

Table

\begin{tabular}{|l|c|}
\cline { 2 - 2 } \multicolumn{1}{c|}{} & Use of the Present Perfect (\%) \\
\hline CG & 29.77 \\
\hline Exp. G & 22.85 \\
\hline
\end{tabular}

06:

Comparison of the results, Pre-test, Part 2 
If we consider the table above, we will notice a difference of $06.92 \%$ between the $\mathrm{CG}$ and the Exp. G before instruction. We conclude that the CG outperforms the Exp. $G$ in the second part of the pre-test.

Part Three: Fill in the gaps with the appropriate adverb

\begin{tabular}{|c|c|c|c|}
\hline \multirow{3}{*}{$\begin{array}{l}\text { Table 08: } \\
\text { Part 3, } \\
\text { the result }\end{array}$} & & Level of Achievement (\%) & \multirow{3}{*}{$\begin{array}{c}\text { Pre-test, } \\
\text { Comparison }\end{array}$} \\
\hline & $\mathbf{C G}$ & 89.71 & \\
\hline & Exp. G & 85.71 & \\
\hline
\end{tabular}

The two groups got quite similar results in part three of the pre-test. More precisely, the CG's average percentage of correct answers is $89.71 \%$, and that of the Exp. $\mathrm{G}$ is $85.71 \%$. Both groups seem to have a very acceptable knowledge of the adverbs of time that are generally associated with the Present Perfect tense, they rarely failed to select the right choice out of four suggested adverbs.

- Results of the Post-test

Part One: Activity One: Fill in the blanks with the correct form of the tense out of two suggested tenses in the following dialogues

In the preceding sub section, we compared the results obtained by CG and the Exp. G in the pre-test. In this section, we will compare the results of the two groups in the post test. The following tables are used as illustrations to clarify things out.

\begin{tabular}{|l|c|c|}
\cline { 2 - 3 } \multicolumn{1}{l|}{} & Use of the Present Perfect & Use of the Past Simple \\
\hline CG & 47.01 & 89.28 \\
\hline Exp. G & 55.58 & 84.28 \\
\hline
\end{tabular}

Table 09: Comparison of the results, Post-test, Part 1

When we compare the learners' obtained results in the post-test for both the CG and the Exp. G, we find that $55.98 \%$ is the average percentage of correct answers which require the use of the present perfect tense for the Exp. G. However, the average of correct answers which require the learners to choose the present perfect tense is only $47.01 \%$ for the CG. 
The difference in performance between the two groups in this first part of activity one in the post test is $08.57 \%$.

Part Two: Fill in the blanks in the following sentences

The table below presents the average percentages of the use of the present perfect in the post-test, part two.

\begin{tabular}{|l|l|c|}
\cline { 2 - 2 } \multicolumn{1}{c|}{ Table 10: } & Use of the Present Perfect (\%) \\
\hline Exp. G & 31.42 \\
\hline & 34.57 \\
\hline
\end{tabular}

Comparison of the results, Post-test, Part 2

In the post-test, part two, quarter of the learners in the CG and the Exp. $\mathrm{G}$ scored well as to the use of the present perfect tense. The average percentage of correct answers is $31.42 \%$ for the CG, and $34.57 \%$ for the Exp. G. The difference in performance between the two groups is $03.15 \%$ that is considered as a very slight difference.

Part Three: Multiple Choice

The learners when asked to choose the right adverb to fill in the gaps, they provided very positive responses. The average percentage of correct answers for the $C G$ and the Exp. $G$ are summed up in the table below.

\begin{tabular}{|c|c|c|c|}
\hline \multirow{3}{*}{$\begin{array}{l}\text { Table 11: } \\
\text { Part 3, }\end{array}$} & & Level of Achievement (\%) & \multirow{3}{*}{$\begin{array}{l}\text { Post-test, } \\
\text { Comparison }\end{array}$} \\
\hline & CG & 91.42 & \\
\hline & Exp. G & 71.31 & \\
\hline
\end{tabular}

According to table 4.136 above, the learners in the CG performed better than the learners in the Exp. $G$ in part three of the post test.

\subsection{Overall Analysis}

When we compare the CG results in the pre-test and post test, we find that the learners in the CG maintained the same level of performance in the pre-test and post test. $48.01 \%$ of them used the present perfect correctly for the first activity in the pre-test and this percentage has almost remained the same and decreased very slightly, it becomes $47.01 \%$. For the second part of the test, $29.77 \%$ of the learners in the CG used the present perfect adequately in the pre-test, and this level has increased a bit in the post-test, it has become $31.42 \%$. Finally, for the third part of the test, the CG performance in the pre-test and the post-test has remained 
almost the same. It was $89.71 \%$ in the pre-test and becomes $91.42 \%$ in the post-test. As far as the Exp. $\mathrm{G}$ is concerned, the results have changed to the better to some extent. For the first part, the learners' performance concerning the use of the present perfect has been $43.89 \%$ which has become $55.58 \%$ in the post-test. In the second part of the test, the learners' use of the present perfect has increased compared to the pre-test; $34.57 \%$ of the learners used the present perfect correctly in the post-test, while only $22.85 \%$ did so in the pre-test. For the last part of our test, the learners' performance did not develop considerably, it rather diminished. It was $85.71 \%$ in the pre-test and has become $71.31 \%$ in the post-test. The average percentage of the correct use of the present perfect for the Exp. $\mathrm{G}$, in the post test, for parts one and two is $45.07 \%$. However, it was $33.37 \%$. On the other hand, the average percentage of the correct use of the present perfect in the post test for the CG is 39.31. It was $38.91 \%$. The level of improvement for the Exp. $\mathrm{G}$ is $11.70 \%$ and for the $\mathrm{CG}$ is $0.4 \%$. On the basis of the comparison between the learners' performances in the pre-test and post test, both for the CG and the Exp. G, we can conclude that learners in the Exp. G outperform those in the CG to some extent. Our second hypothesis has been partially confirmed, in other words, Role Play has helped learners to understand and use the Present Perfect tense.

The analysis and interpretation of the results show that the second hypothesis, which suggests that using Role Play to teach the Present Perfect can help learners understand and use this tense adequately, has been partially confirmed. The use of Role Play to teach the present perfect has proved to be effective to a certain degree. This has been revealed from the analysis of the results for the Exp. G in the post test which has shown that there exists an improvement in the learners' responses to the different parts of the test. we have the firm conviction that if it had been possible for us to apply the new treatment for a longer period of time, the results would have been better.Learners' confusions between the very functions of the Present Perfect and the past simple have led to the overgeneralization of the use of the past simple tense, and thus neglecting the use of the Present Perfect tense. However, the use of Role Play has helped learners understand and practise the present perfect when expressing some past events that are strongly related to the present as they imply that what has happened in the past has some sort of connection to the present.

\section{Conclusion}


Achieving successful teaching is not an easy task; researcher teachers should always try new ideas in their language classes until they succeed to find the best method to teach the subject matter they are assigned to. The present research is considered as one attempt to manipulate two variables that are 'teaching the Present Perfect tense' and 'Role Play', which has resulted in a considerable level of improvement and effectiveness in the learners' performance in understanding and using the Present Perfect.

\section{Referenses}

Comrie, B. (1976). Aspect: An introduction to the Study of Verbal Aspect and Related Problems. Cambridge: Cambridge University Press. (Cambridge textbooks in linguistics).

Declerck, R. (2015). Tense in English: Its Structure and Use in Discourse. Routledge: New York.

Declerck, R., \& Reed, S., \& Capelle, B. (2006). In K. Bernd \& E. C. Traugott (Eds.). The Grammar of the English Tense System: A Comprehensive Analysis (Vol. 1). Mouton de Gruyter: New York..

Killen, R. (2007). Teaching Strategies for Outcomes-based Education. ( $\left.2^{\text {nd }} E d.\right)$. South Africa: JUVA \& Co. Ltd.

Ladousse, G. P. (1987). Role Play. In A. Maley (Ed.). Resource books for Teachers. Oxford: Oxford University Press.

Leech, G. (2014). Meaning and the English Verb. ( $3^{\text {rd }}$ Ed.). Pearson Education Limited: New York. (Routledge).

Purpura, J. E. (2004). In J. Charles Alderson \& Lyle F. Bachman (Eds.). Assessing Grammar. Cambridge: Cambridge Language Assessment Series.

Scrivener, J. (2010). Teaching English Grammar: What to Teach and How to Teach it. Macmillan Published Limited: London.

Thournbury, S. (1999). In J. Harmer (Ed.) How to Teach Grammar. England: Pearson Education Limited. 